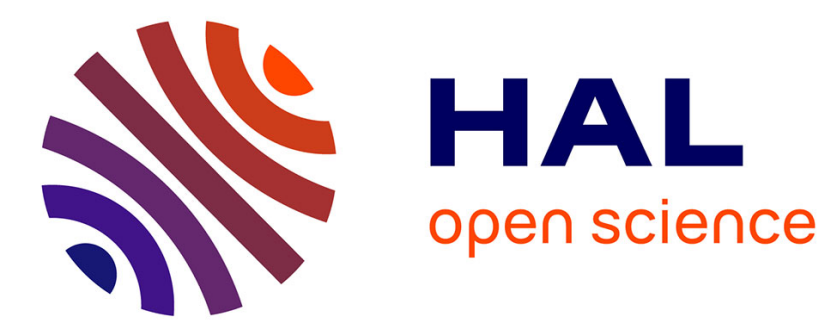

\title{
Deposition of BaFe12O19 Thin Films by a New Injection-CVD Method
}

S. Pignard, J. Sénateur, H. Vincent, J. Kreisel, A. Abrutis

\section{To cite this version:}

S. Pignard, J. Sénateur, H. Vincent, J. Kreisel, A. Abrutis. Deposition of BaFe12O19 Thin Films by a New Injection-CVD Method. Journal de Physique IV Proceedings, 1997, 07 (C1), pp.C1-483-C1-484. 10.1051/jp4:19971196 . jpa-00254846

\section{HAL Id: jpa-00254846 https://hal.science/jpa-00254846}

Submitted on 1 Jan 1997

HAL is a multi-disciplinary open access archive for the deposit and dissemination of scientific research documents, whether they are published or not. The documents may come from teaching and research institutions in France or abroad, or from public or private research centers.
L'archive ouverte pluridisciplinaire HAL, est destinée au dépôt et à la diffusion de documents scientifiques de niveau recherche, publiés ou non, émanant des établissements d'enseignement et de recherche français ou étrangers, des laboratoires publics ou privés. 


\title{
Deposition of $\mathrm{BaFe}_{12} \mathrm{O}_{19}$ Thin Films by a New Injection-CVD Method
}

\author{
S. Pignard, J.P. Sénateur, H. Vincent, J. Kreisel and A. Abrutis*
}

\author{
L.M.G.P., UMR 5628 du CNRS, E.N.S. de Physique de Grenoble, 38402 Saint-Martin d'Hères, France \\ * Department of General and Inorganic Chemistry, Faculty of Chemistry, Vilnius University, 2734 \\ Vilnius, Lithuania
}

\begin{abstract}
A new process of injection-MOCVD has been used to synthesize barium hexaferrite thin films on $\mathrm{Al}_{2} \mathrm{O}_{3}(0001)$ substrates. This new technique uses a liquid source of precursors dissolved in a convenient solvent. X-ray diffraction measurements have been performed to observe thin films lattices with respect to the orientation of the substrate : hexaferrite film epitaxy is observed with c-axis perpendicular to the substrate. Magnetic measurements have been performed in the plane and perpendicular to the film plane : they confirm the preferential orientation of films.
\end{abstract}

\section{INTRODUCTION}

Films of barium hexaferrite ( $\mathrm{BaM}$ ) are of great interest for magnetic recording [1] and for microwave circuit applications. In order to obtain BaM films several techniques have been tested [2] [3] [4] [5]. Here properties of $\mathrm{BaFe}_{22} \mathrm{O}_{19}$ thin films deposited by a new method called injection-CVD [6] are described. Results obtained for films grown on $\mathrm{Al}_{2} \mathrm{O}_{3}(0001)$ are presented.

\section{EXPERIMENTAL PROCEDURE}

In the new process presented here, solid precursors of $\mathrm{Ba}$ (thd)2 and $\mathrm{Fe}$ (thd)3 are dissolved in 1,2-dimethoxy-ethane ; the solution is placed in a hermetically closed vessel under argon which is connected to an injector. Droplets of few microliters are sequentially injected from this liquid source. Vapours of barium and iron precursors are produced by heating the injected droplets ; these vapours are then used in a conventional hot-wall CVD reactor.

Film growth has been performed under the following conditions :

\begin{tabular}{llll}
\hline & & & \\
Injection zone temperature & $25^{\circ} \mathrm{C}$ & Ba dilution & $0.003 \mathrm{~mol} / 1$ \\
Evaporator temperature & $250^{\circ} \mathrm{C}$ & Fe dilution & $0.027 \mathrm{~mol} / 1$ \\
Substrate temperature & $800^{\circ} \mathrm{C}$ & Volume of droplets & $5.0 \mu 1$ \\
Total pressure & $5.0 \mathrm{hPa}$ & Number of droplets & 700 \\
Oxygen flow & $900 \mathrm{~cm}^{3} / \mathrm{min}$ & Injection frequency & $1 \mathrm{~Hz}$ \\
Argon flow & $300 \mathrm{~cm}^{3} / \mathrm{min}$ & & \\
\hline
\end{tabular}

\section{RESULTS AND DISCUSSION}

\subsection{X-Ray diffraction}

Figure 1 displays the XRD pattern of a $\mathrm{BaFe} 12 \mathrm{O} 19$ as-deposited film performed in the conventional $\theta / 2 \theta$ scanning mode $\left(\lambda \mathrm{Cu}_{4}=1.54056 \AA\right)$; the film is $2500 \AA$ thick and the surface is $1 \times 1 \mathrm{~cm}^{2}$. For our films grown on $\mathrm{Al}_{2} \mathrm{O}_{3}(0001)$ the only intense peaks of the $\mathrm{BaM}$ phase are the $(00 \ell)$ indicating a very good orientation with the c-axis perpendicular to the film plane.

The $\theta / 2 \theta$ XRD scan indicates parallelism between the [001] direction of the BaM phase and the [001] direction of the sapphire substrate but reveals nothing about in-plane orientation. Figure 2 displays the $\{1017\}$ pole density of $\mathrm{BaFe}_{2} \mathrm{O} 19$ obtained for its Bragg angle. The six equivalent directions $<107>$ appear for $\chi=33^{\circ}$ which indicates an epitaxial growth of the hexaferrite film. The full-width at half-maximum (FWHM) of the rocking curve performed on the 008 diffraction line of the Ba-ferrite is $0.79^{\circ}$ showing the high orientation of the layer. This value of FWHM has to be compared with that of $0.32^{\circ}$ obtained for the rocking curve performed on the 006 diffraction line of the sapphire substrate. 


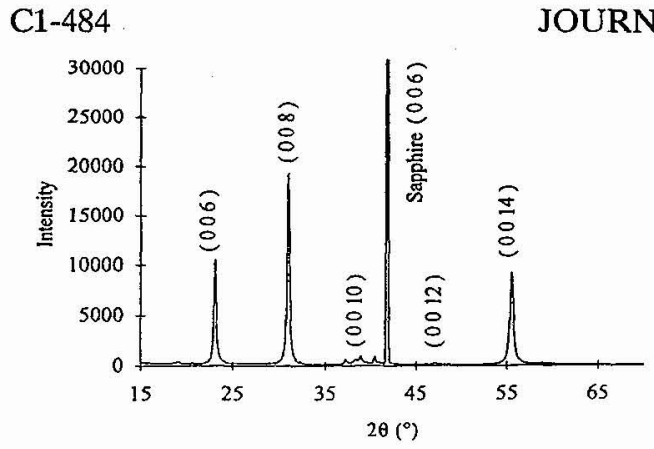

Figure I : XRD pattern of BaM film
OURNAL DE PHYSIQUE IV

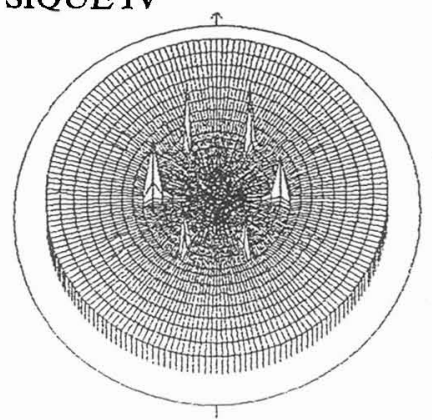

Figure $2:\{10 \overline{\mathrm{I}} 7\}$ pole density of BaM film

\subsection{Magnetic measurements:}

Figures 3 and 4 show the first magnetization curves performed with a vibrating sample magnetometer. The field was applied parallel and perpendicular to the film plane respectively. Barium hexaferrite has strong axial magnetocrystalline anisotropy; the anisotropy of samples is determined by both the crystal anisotropy and the shape anisotropy of the thin film geometry. When the field is applied in the film plane the demagnetizing effect is negligible. This is not the case when $\mathrm{H}$ is perpendicular to the film, i.e. parallel to the easy direction of $\mathrm{BaM}$; the demagnetizing field factor has been evaluated using the formula for an oblate ellipsoid and has been corrected on figure 4.

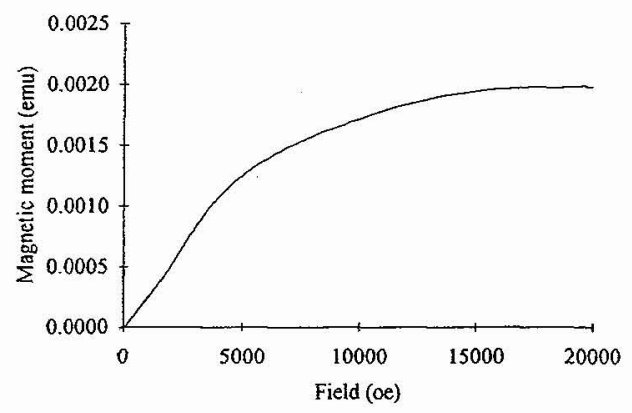

Figure $3: \mathrm{H} / /$ to the film plane

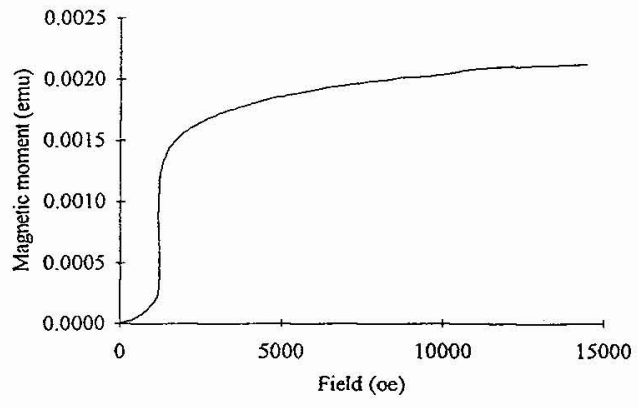

Figure $4: \mathrm{H} \perp$ to the film plane

When the field is applied in the plane of the film, the observed anisotropy field is about 17000 Oe which is the value usually obtained on a single crystal. When the field is perpendicular to the film there is competition between shape and magnetocrystalline anisotropies. Until 1200 Oe the shape anisotropy is stronger so that the magnetization increases slowly. Then there is a strong increase in relation to the rotation and a quick development of magnetic domains. After 2000 Oe the magnetic moment increases more slowly by rotation mechanism of the domains until the saturation for a field of 10000 Oe. These two curves show that the easy direction of magnetization is the c-axis but also that the magnetic moments are not parallel to the c-axis but canted.

\section{CONCLUSION}

A new injection-CVD method has been successfully used to deposite epitaxial films of BaFei2O19 on sapphire (0001). Magnetic measurements show that the easy direction of magnetization is the c-axis which is perpendicular to the substrate, but that the magnetic structure is canted.

\section{References:}

(1) E. Koster, J. Magn. Magn. Mater., 120, 1 (1993)

(2) T.L. Hylton, M.A. Parker, K.R. Coffey, J.K. Howard, J. Appl. Phys, 73 (10), 6257 (1993)

(3) X. Sui, M.H. Kryder, Appl. Phys. Lett, 63, 1582 (1993)

(4) C.A. Carosella, D.B. Chrisey, P. Lubitz, J.S. Horwitz, P. Dorsey, R. Seed, C. Vittoria, J. Appl. Phys., 71, 5107 (1992)

(5) E.J. Donahue, D.M. Schleich, J. Appl. Phys., 71, 6013 (1992)

(6) F. Felten, J.P. Sénateur, F. Weiss, R. Madar, A. Abrutis, Journal de Physique IV, C5-1079 (1995) 